RECEIVED

NOV 211995

OSAI

\title{
Revised Validation of Thermal- Hydraulic Model of SCWO Bench Scale Reactor
}

Robert J. Kochan

Chang H. Oh 
This report was prepared as an account of work sponsored by an agency of the United States Government. Neither the United States Government nor any agency thereof, nor any of their employees, makes any warranty, express or implied, or assumes any legal liability or responsibility for the accuracy, completeness, or usefulness of any information, apparatus, product, or process disclosed, or represents that its use would not infringe privately owned rights. Reference herein to any specific commercial product, process, or service by trade name, trademark, manufacturer, or otherwise does not necessarily constitute or imply its endorsement, recommendation, or favoring by the United States Government or any agency thereof. The views and opinions of authors expressed herein do not necessarily state or reflect those of the United States Government or any agency thereof.

\title{
REVISED VALIDATION OF THERMAL-HYDRAULIC MODEL OF SCWO BENCH SCALE REACTOR
}

\author{
R.J. Kochan \\ C.H. Oh
}

F'ublished October 1995

\section{Idaho National Engineering Laboratory Lockheed Idaho Technologies Company Idaho Falls, Idaho 83415}

\author{
Prepared for the \\ U.\$s. Department of Energy \\ Assistant Secretary for Environmental Management \\ Under DOE Idaho Operations Office \\ Contract No. DE-AC07-94ID13223
}

INEL-95/0520 


\section{ABSTRACT}

The FLUENT computer code was used to construct a coupled fluid flow-chemical kinetics model of a MODAR bench scale reactor. This model predicted temperatures measured during MODAR test run 523.F very satisfactorily but required some modification to the measured boundary conditions. Several improvements to the model were made during a similar study of a MODAR pilot scale reactor. This report presents a rerun of the bench scale results using the updated model and shows better predictions than the initial runs. As before, the results of these calculations indicate that for better model validation, we need to obtain more accurate boundary conditions in future test runs. 


\section{DISCLAIMER}

Portions of this document may be illegible in electronic irnage products. Images are produced from the best available original document. 


\section{SUMMARY}

In the SCWO process, organics, are oxidized in the presence of air and water at conditions above the critical temperature and pressure of water. This process is being evaluated by the U.S. DOE for extension to the treatment of mixed wastes by investigating the performance of bench and pilot scale units in treating hazardous wastes and surrogate mixed wastes. Since these small scale units have proven to be very effective waste reducers, it is desired to scale them up to the size of a production facility.

In order to use the small scale results properly in designing the larger scale units, it is necessary to create coupled flow-chemical kinetics model of the bench and pilot scale SCWO reactors, validate their accuracy against the measured data, and then use the same modeling techniques to extrapolate the results to the larger scales. Then, when the larger scale plant is built and tested, the extrapolation procedures can themselves be validated for subsequent use.

The detailed flow-chemical kinetics models will also provide the capability of modeling the effects of chemical corrosion and salt formation, which, too, are strongly coupled to the flow and chemical compositions. No simple scaling will be able to predict the magnitudes and extent of these effects, and extrapolation from a specific test condition to another would be extremely difficult, if not impossible, without a coupled code.

A previous report presented the rationale used to select a CFD code for SCWO reactor thermal hydraulic studies, and then, using the selected code, a model of a MODAR bench-scale vessel reactor was made and compared with test results from that MODAR reactor. Subsequent to that study, another CFD model was created for a MODAR pilot scale reactor and test. During the pilot scale study, the model was improved in several areas. We have now rerun the bench scale study with the more accurate model and have found that the results are more consistent. This report summarizes these final results for MODAR Run 523.f.

Although the results of the model have been improved, this study still shows that more accurate boundary conditions (e.g., input flows and temperatures, wall temperatures) are required to be able to perform a model validation. 


\section{CONTENTS}

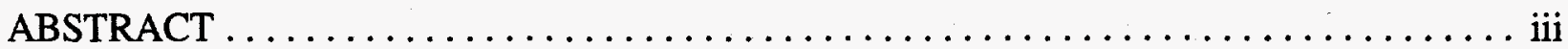

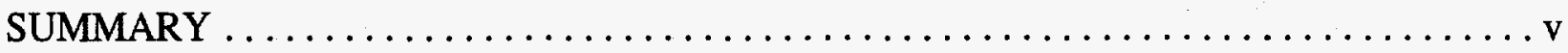

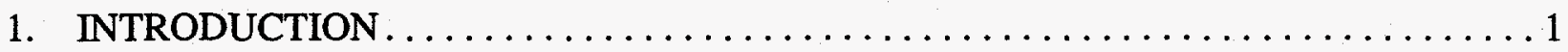

2. SCWO VESSEL REACTOR MIODEL AND ASSUMPTIONS ................

2.1 Vessel Reactor Geometry and CFD Model $\ldots \ldots \ldots \ldots \ldots \ldots \ldots \ldots \ldots \ldots \ldots$

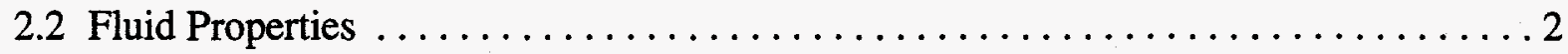

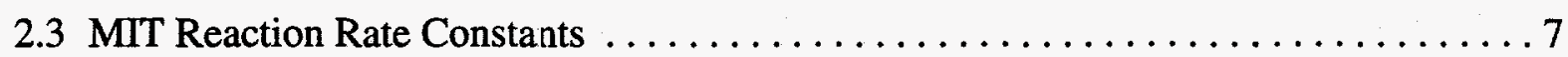

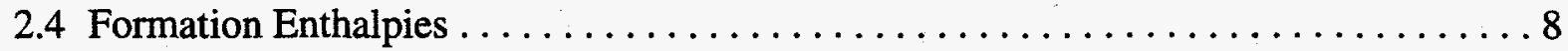

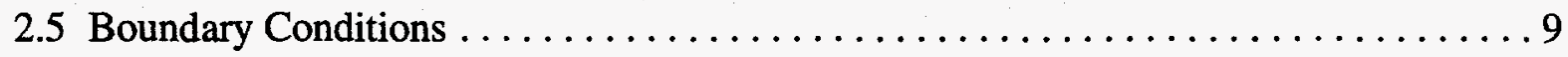

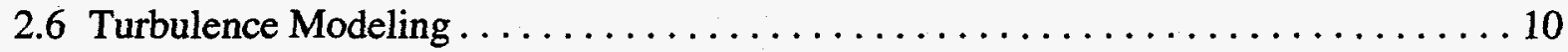

3. MODAR RUN 523.F RUN SEIRIES RESULTS. $\ldots \ldots \ldots \ldots \ldots \ldots \ldots \ldots \ldots \ldots$

3.1 Temperature Predictions. . . . . . . . . . . . . . . . . . . . . . . . . 11

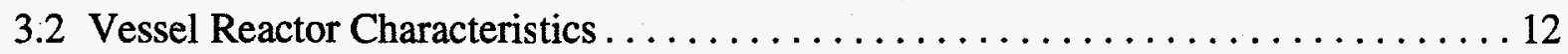

3.2.1 Recirculation Pattern. . . . . . . . . . . . . . . . . . . . . . . 12

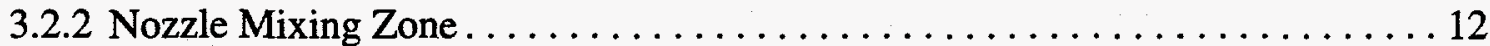

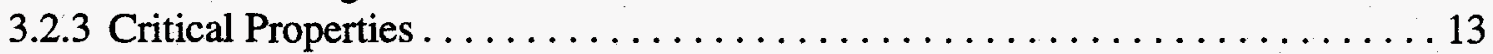

3.2.4 MTT vs. MODAR Kinetic Constants $\ldots \ldots \ldots \ldots \ldots \ldots \ldots \ldots \ldots \ldots \ldots$

4. CONCLUSIONS AND RECOIMMENDATIONS $\ldots \ldots \ldots \ldots \ldots \ldots \ldots \ldots \ldots \ldots \ldots$

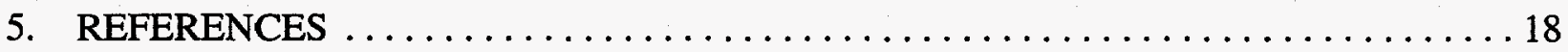




\section{FIGURES}

1. FLUENT model of MODAR bench scale vessel reactor in vicinity of nozzle tip showing radial model discretization. . . . . . . . . . . . . . . . . . . . . . . . 3

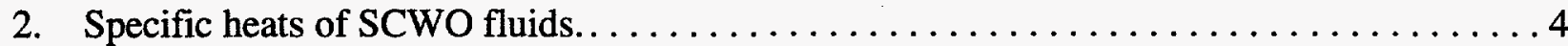

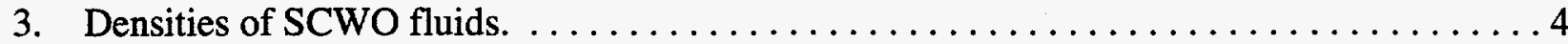

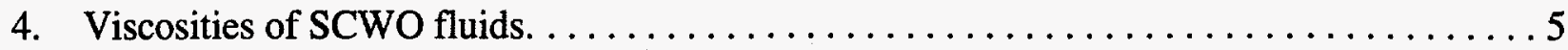

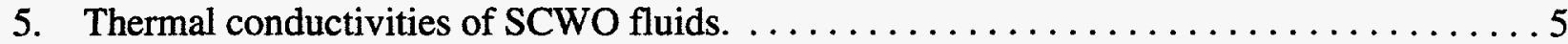

6. Comparison of water specific heat calculated from NBS steam tables with the approximation used in FLUENT model at 3400 psia and near the critical

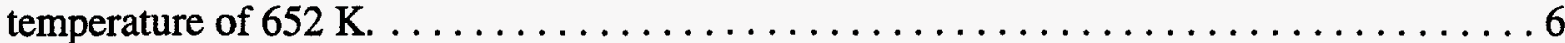

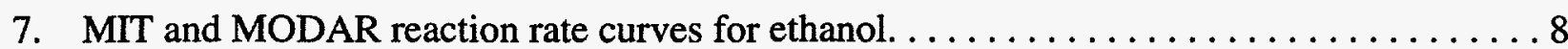

8. FLUENT predicted fluid temperatures for MODAR Run 523.f. ............. 11

9. Comparison of MODAR test data with FLUENT predicted temperatures. . . . . . . 12

10. Region of the reactor with temperatures between 327 and $427^{\circ} \mathrm{C}$. Peak water

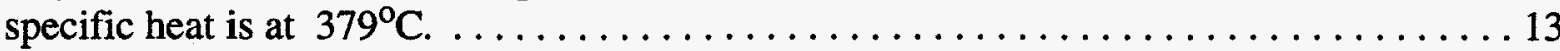

11. Comparison of FLUENT results using MIT and MODAR kinetic rate equations. Reaction rate and mass fraction contours are factors of 10; fluid temperatures are $20^{\circ} \mathrm{C}$. Shaded areas in reaction rates show regions of highest rates...........

12. Arrhenius/Mixing reaction rate ratios for MIT and MODAR rate equations. Levels below 1 are kinetics limited; greater than 1 are diffusion limited. .

\section{TABLE}

1. Specie formation enthalpies for SCWO of ethanol in air.................. 9 


\section{REVISED VALIDATION OF THERMAL-HYDRAULIC MODEL OF SCWO BENCH SCALE REACTOR}

\section{INTRODUCTION}

Reference 1 detailed the analytical modeling requirements for the thermal hydraulic analysis of a supercritical water oxidation (SCWO) pilot plant and recommended that the FLUENT and PHOENICS computational fluid dyramics (CFD) computer codes be evaluated to determine their suitability in modeling these complex phenomena. Reference 2 presented initial modeling attempts and results comparisons for the two codes; the models used in that report were approximations of the MODAR vessel reactor configuration but did not represent actual test conditions as this information was not available to us at that time. Since those preliminary studies, actual proprietary MODAR test data and reactor configurations have been made available to the INEL for use in CFD model development and validation under a cooperative agreement.

Reference 3 documented the selection of the FLUENT CFD computer code for use in modeling the complex flows and multicomponent transport in a SCWO vessel reactor. This reference also documented the initial efforts at: modeling limited bench scale reactor data supplied by MODAR. These results showed that the FLUENT model could provide a valuable insight into the flow characteristics inside the reactor. Flow boundary conditions had to be modified from the measured values to match the measured fluid temperatures.

Upon completion of the bench scale model, a second FLUENT model ${ }^{4}$ was constructed representing a larger (pilot scale) vessel reactor from which test data had been collected. As this model evolved, improvements were made in several areas including meshing, solution algorithm, specie properties, and turbulent solid particle transport capabilities. We have subsequently rerun the bench scale case using the pilot scale model improvements and have found that the field variables, such as temperature, are better converged. 


\section{SCWO VESSEL REACTOR MODEL AND ASSUMPTIONS}

The original bench scale FLUENT model and results are detailed in Reference 3 . Reference 4 presents the improved pilot scale model and results. This report will document only the improvements in the bench scale model. The results of the improved calculations, where they are different from those in Reference 4 , are presented and discussed.

\subsection{Vessel Reactor Geometry and CFD Model}

The MODAR bench scale vessel reactor geometry modeled in this study was the same as in Reference 3 . It is difficult to graphically show the entire domain of 286 X 50 (14300 total) cells but Figure 1 indicates the model resolution in the vicinity of the nozzle tip.

FLUENT ${ }^{5}$ solves the full Navier-Stokes equations for compressible chemically reacting flows. The axisymmetric option of the code was used for these calculations. The multigrid solver in FLUENT was used in this study instead of the linear solver used in our earlier study ${ }^{3}$. The multigrid solver converges more rapidly and gives better results in fewer iterations than the linear solver previously used.

\subsection{Fluid Properties}

The critical point of water is at $3206 \mathrm{psia}(22.1 \mathrm{MPa})$ and $374^{\circ} \mathrm{C}$. A SCWO reactor is typically run at a pressure somewhat higher than the critical pressure; the reactor simulated in this report was operated at a constant pressure of $3400 \mathrm{psia}(23.4 \mathrm{MPa})$.

The five chemical species considered in this application include ethanol, water, carbon dioxide, oxygen, and nitrogen. Properties needed for the calculations include the specie densities, specific heats, viscosities, and thermal conductivities. These properties were obtained from the Aspen code ${ }^{6}$ as a function of temperature for the range of $300 \mathrm{~K}$ to $1500 \mathrm{~K}$ and a constant pressure of 3400 psia. The vessel reactor has a relatively low pressure drop so the approximation of constant pressure properties will not introduce a significant error into the calculations. Water properties were calculated using the NBS correlations in the Aspen code, while the properties of the other fluids were calculated with the SR-Polar option. These properties are more consistent than those used in the earlier study in Reference 3 as they are all obtained for the system pressure of 3400 psia (Reference 3 used water properties at 3500 psia) and they are extended to slightly lower temperatures than the $366 \mathrm{~K}$ of Reference 3 .

Figure 2 through Figure 5 show the specific heat, density, viscosity, and thermal conductivity of all the species used in this study and also those of isopropyl alcohol (isopropyl alcohol was used in the pilot scale study in Reference 4 ). 


\section{Reactor outer wall}

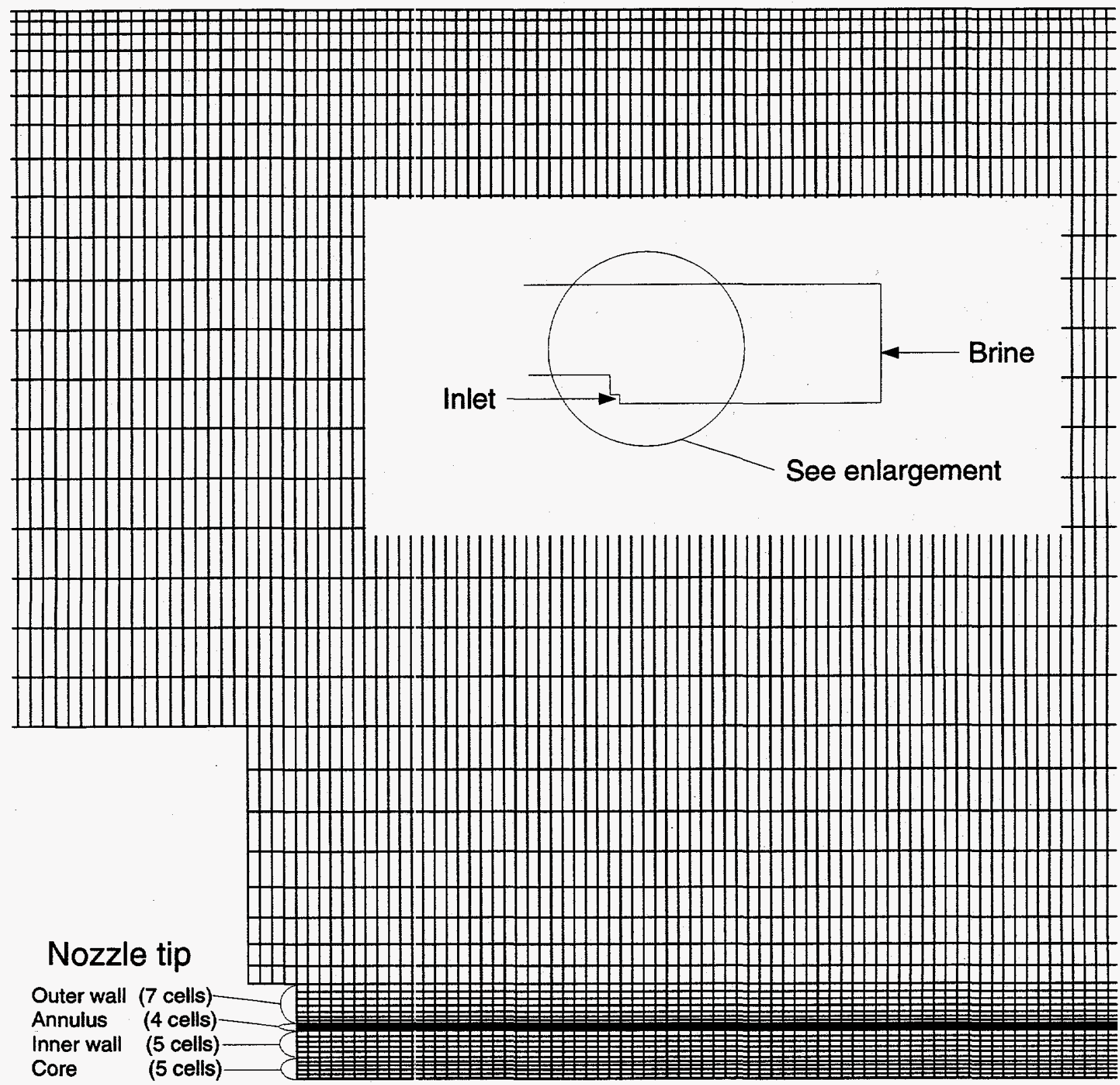

Nozzle centerline

Figure 1. FLUENT model of MODAR bench scale vessel reactor in vicinity of nozzle tip showing radial model discretization. 


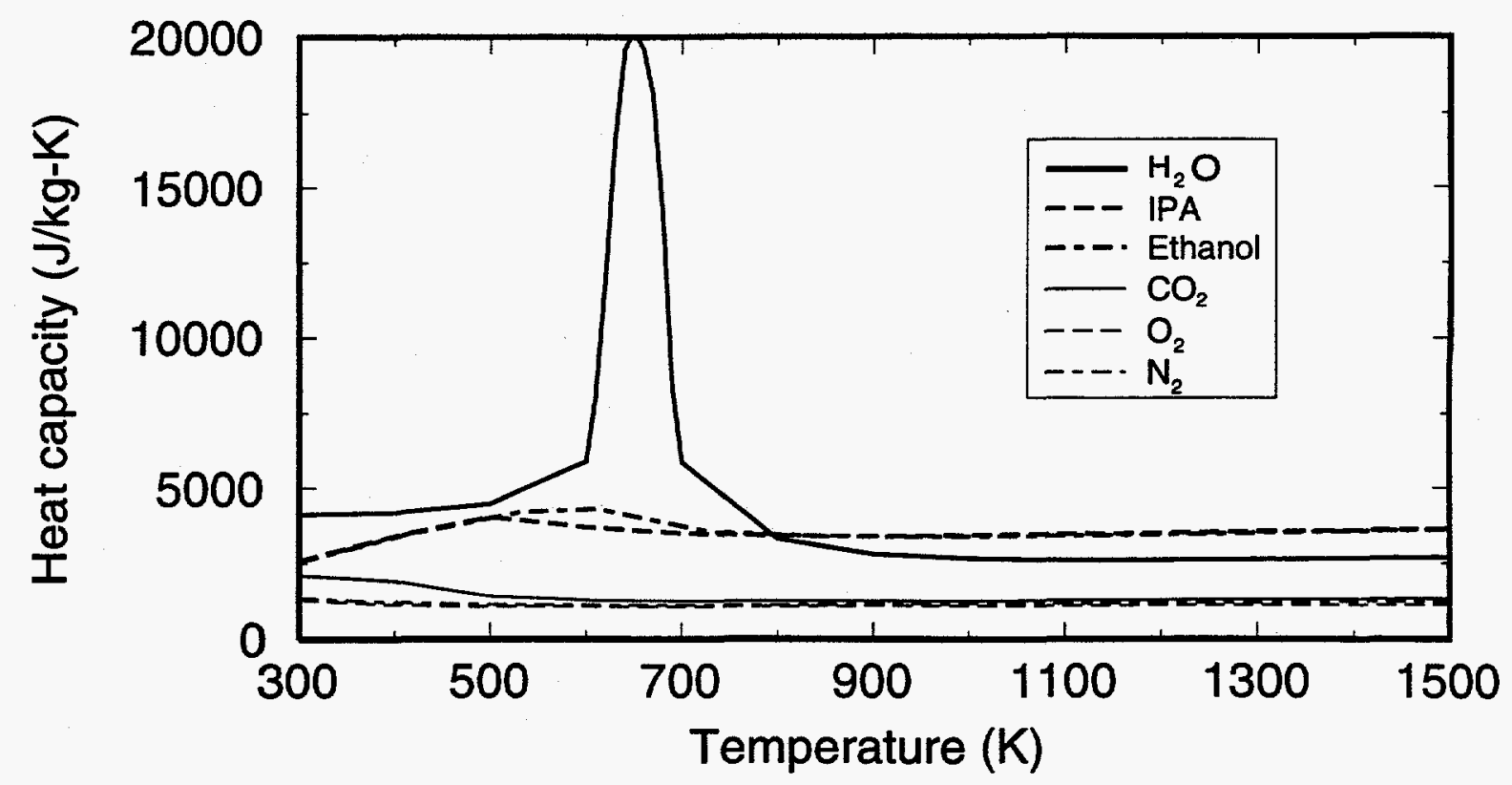

Figure 2. Specific heats of SCWO fluids.

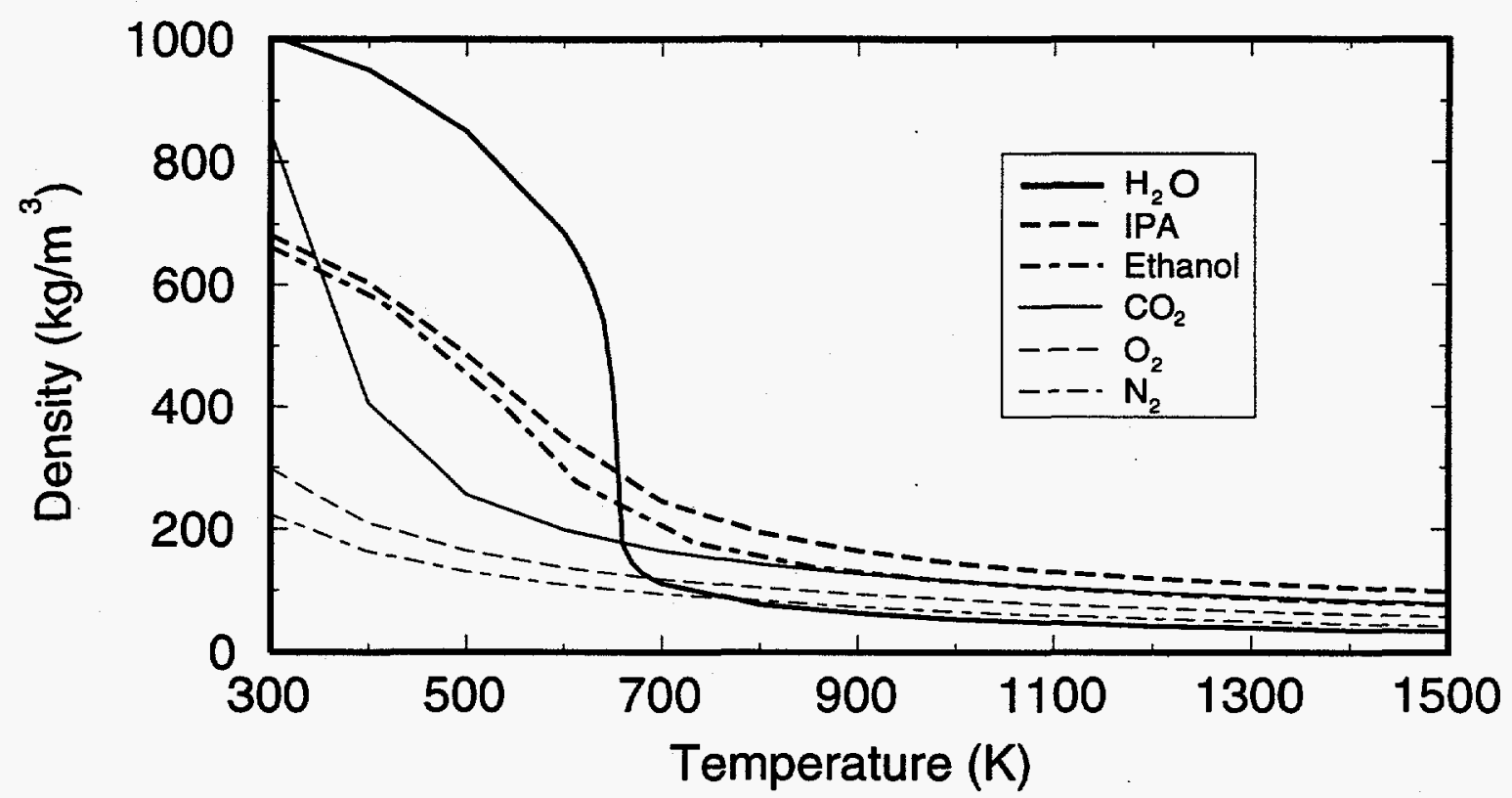

Figure 3. Densities of SCWO fluids. 


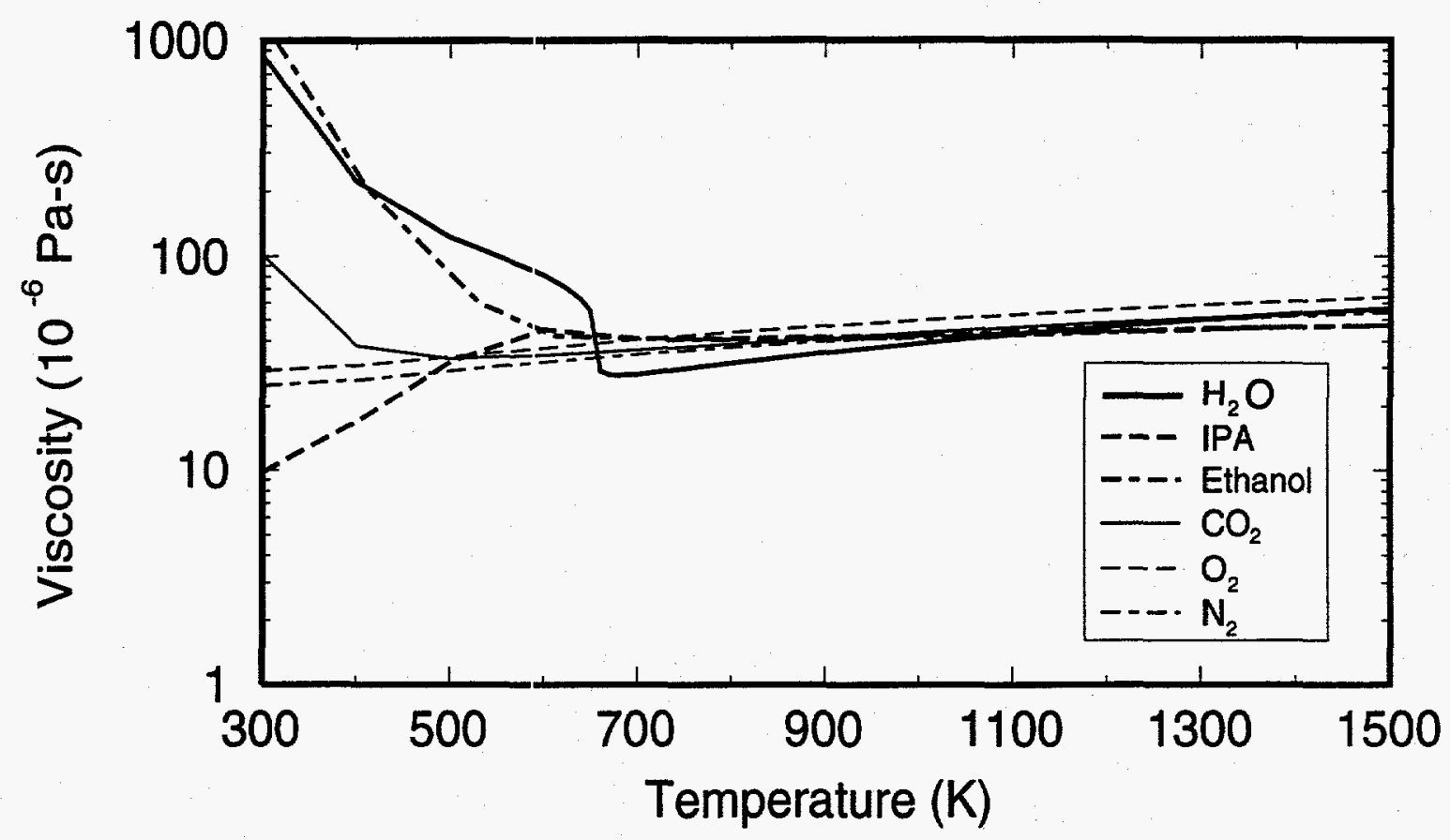

Figure 4. Viscosities of SCWO fluids.

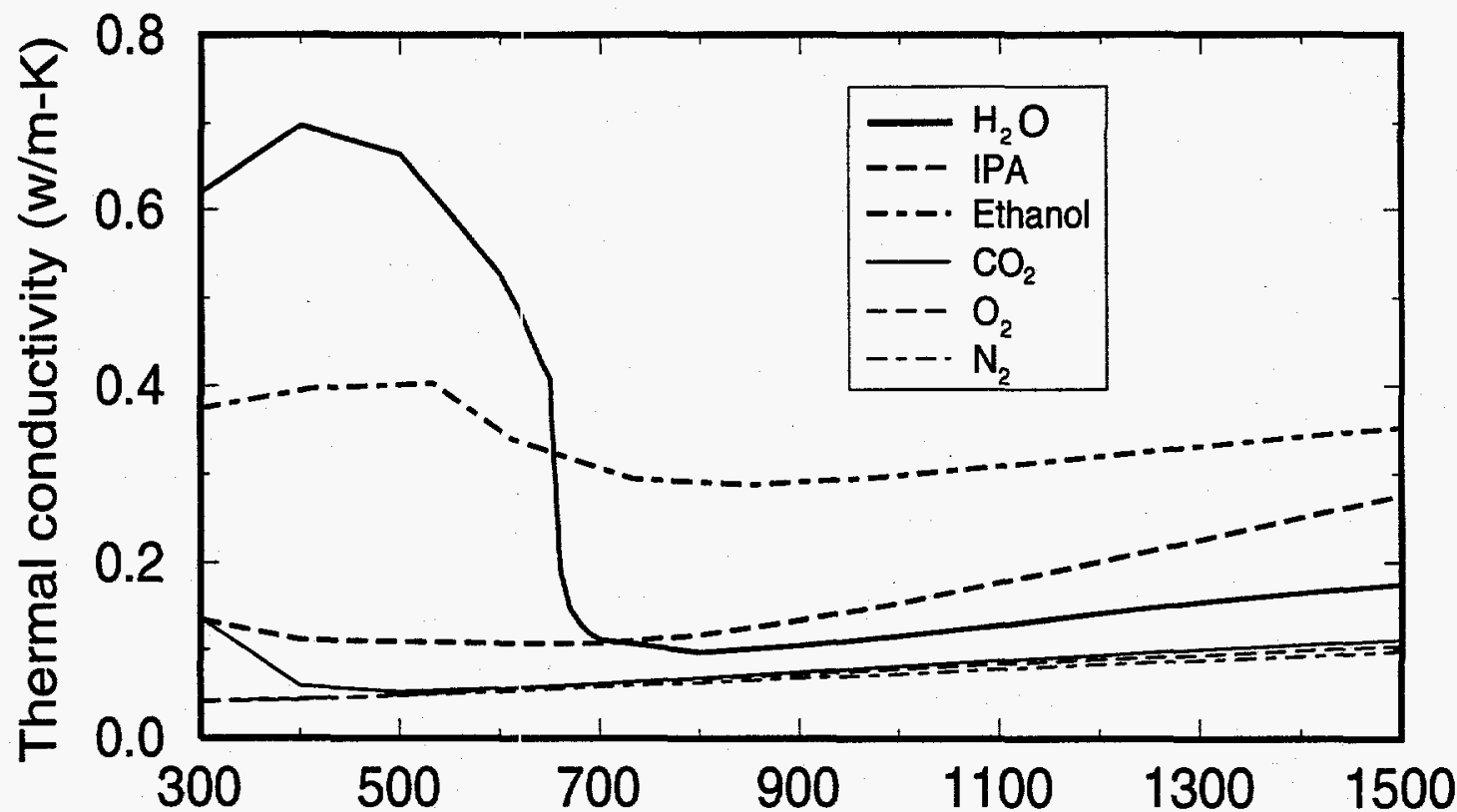

Figure 5. Thermal conductivities of SCWO fluids. 
FLUENT computes the mixture density from the individual specie densities as:

$$
\rho=\frac{1}{\sum_{i} \frac{m_{i}}{\rho_{i}}}
$$

where $m_{i}$ is the mass fraction and $\rho_{i}$ is the density of species $i$.

FLUENT computes the mixture heat capacity, viscosity, and thermal conductivity (shown for heat capacity) as:

$$
c_{p}=\sum_{i} m_{i} c_{p, i}
$$

where $c_{p, i}$ (or $\mu_{i}$ or $k_{i}$ ) are the specie properties.

Figure 6 shows a comparison between the approximations of specific heat of water used in this study and the values predicted using the ASPEN NBS steam tables in Reference 6 . Figure A.37 in Reference 7 shows that the NBS steam tables are very accurate in the vicinity of the critical point. As was done in Reference 3 , the specific heat of water near the critical point was

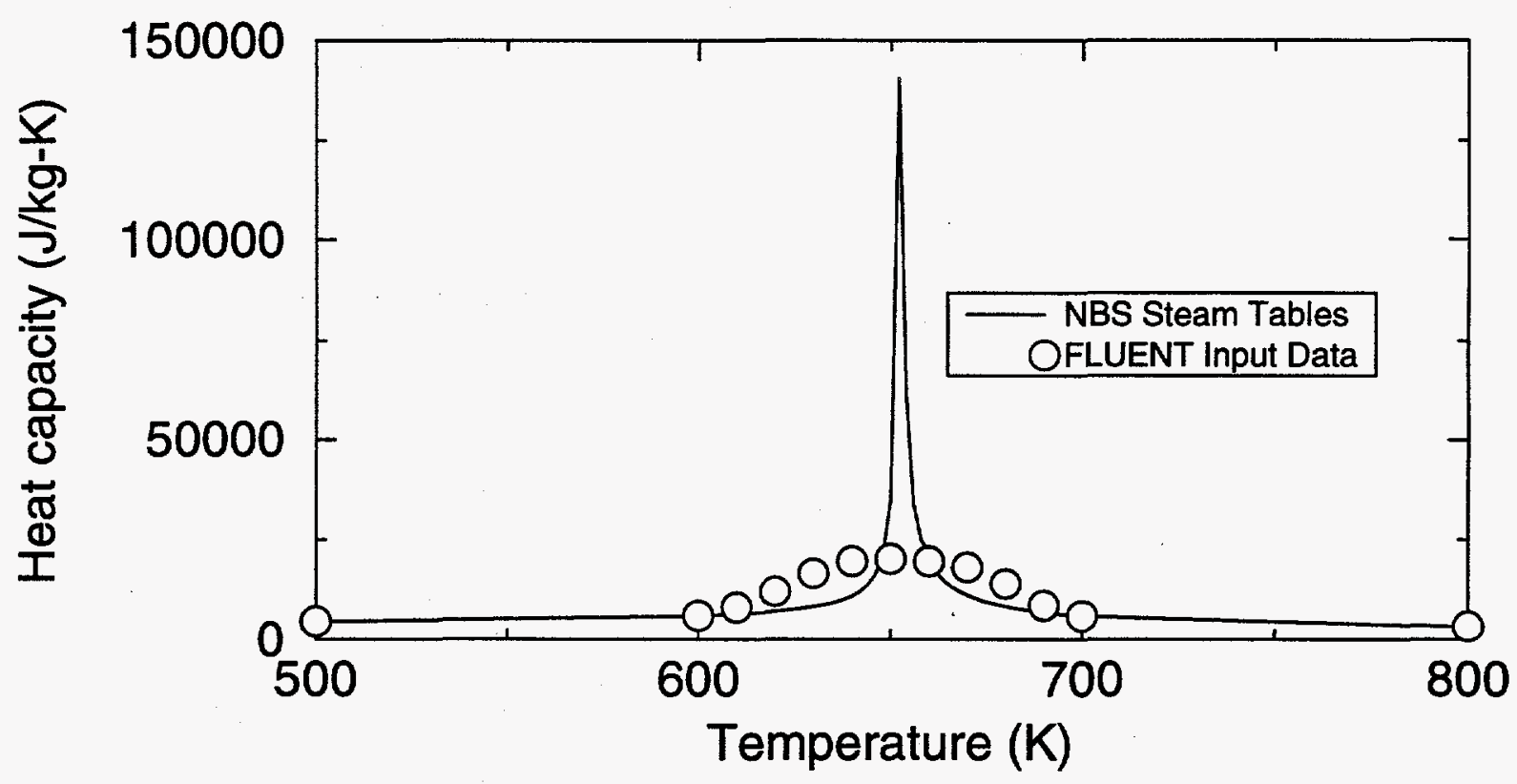

Figure 6. Comparison of water specific heat calculated from NBS steam tables with the approximation used in FLUENT model at 3400 psia and near the critical temperature of $652 \mathrm{~K}$. 
smoothed to enhance the stability and convergence of the numerical solution. Whereas the approximation used in Reference 3 was a simple triangular spike over the temperature range of $600 \mathrm{~K}$ to $700 \mathrm{~K}$, the approximation used in this study was a somewhat rounder curve in an attempt to improve the stability of the solution. The approximate curve was computed to ensure that the integral of the curve was the same as that from the NBS curve so that temperatures in the reactor in regions outside this range are calculated accurately.

\subsection{MIT' Reaction Rate Constants}

The ethanol kinetics used in this study approximates the multistep ethanol oxidation reaction by the single step reaction:

$$
\mathrm{C}_{2} \mathrm{H}_{5} \mathrm{OH}+3 \mathrm{O}_{2} \rightarrow 2 \mathrm{CO}_{2}+3 \mathrm{HI}_{2} \mathrm{O}
$$

The reaction rate approximation used in the FLUENT model was first order in ethanol with a two parameter Arrhenius rate constant:

$$
R_{\text {ETHANOL }}=-M_{\text {ETHANOL }} C_{\text {ETHANOL }} A_{\text {ETHANOL }} \exp \left(-\frac{E_{\text {ETHANOL }}}{R_{u} T}\right) .
$$

where $R_{\text {ETHANOL }}$ is the mass rate of creation of ethanol in each cell, $M_{E T H A N O L}$ is the molecular weight of ethanol, $C_{E T H A N O L}$ is the molar concentration of ethanol, $R_{u}$ is the universal gas constant, and $T$ is the fluid temperature.

The Massachusetts Institute of Technology (MIT) rate constants ${ }^{8, a}$ were used for most of the calculations in this simulation. The MIT kinetic rate constants are:

Pre-exponential factor, $A=6.456 \mathrm{E} 211 / \mathrm{sec}$

Activation energy, $\quad \mathrm{E}=3.397 \mathrm{E} 08$ Joules $/ \mathrm{kgmol}$

A second set of rate constants, calculated by $\operatorname{MODAR}^{\mathrm{a}}$ from test data in a pipe reactor, were also considered in this study. The MODAR kinetic rate constants are:

Pre-exponential factor, $\mathrm{A}=7.482 \mathrm{E} 041 / \mathrm{sec}$

Activation energy, $\quad \mathrm{E}=6.203 \mathrm{E} 07$ Joules $/ \mathrm{kgmol}$

This data was regressed from non-isothermal pipe reactor temperature data, where a cold $\left(25^{\circ} \mathrm{C}\right)$ ethanol/water stream was mixed and reacted with a hot $\left(550^{\circ} \mathrm{C}\right)$ water/air stream.

a. A. Bourhis, MODAR Letter to T. Charlton, "Summaries of four MODAR experiments," MODAR confidential information, August 24, 1994. 
MODAR's kinetic rates from data taken in this manner are, in general, considerably higher for temperatures less than $581^{\circ} \mathrm{C}$ than equivalent data taken by others (e.g., the MIT data also documented in a). Figure 7 graphically shows the two Arrhenius equations.

MODAR has indicated to us that their data may not meet the usual standards associated with kinetics studies. This difference is believed to be due to non-isothermal inlet conditions in the MODAR test. We investigated the effect of these two rate equations on the reaction zone shapes; the results will be discussed later.

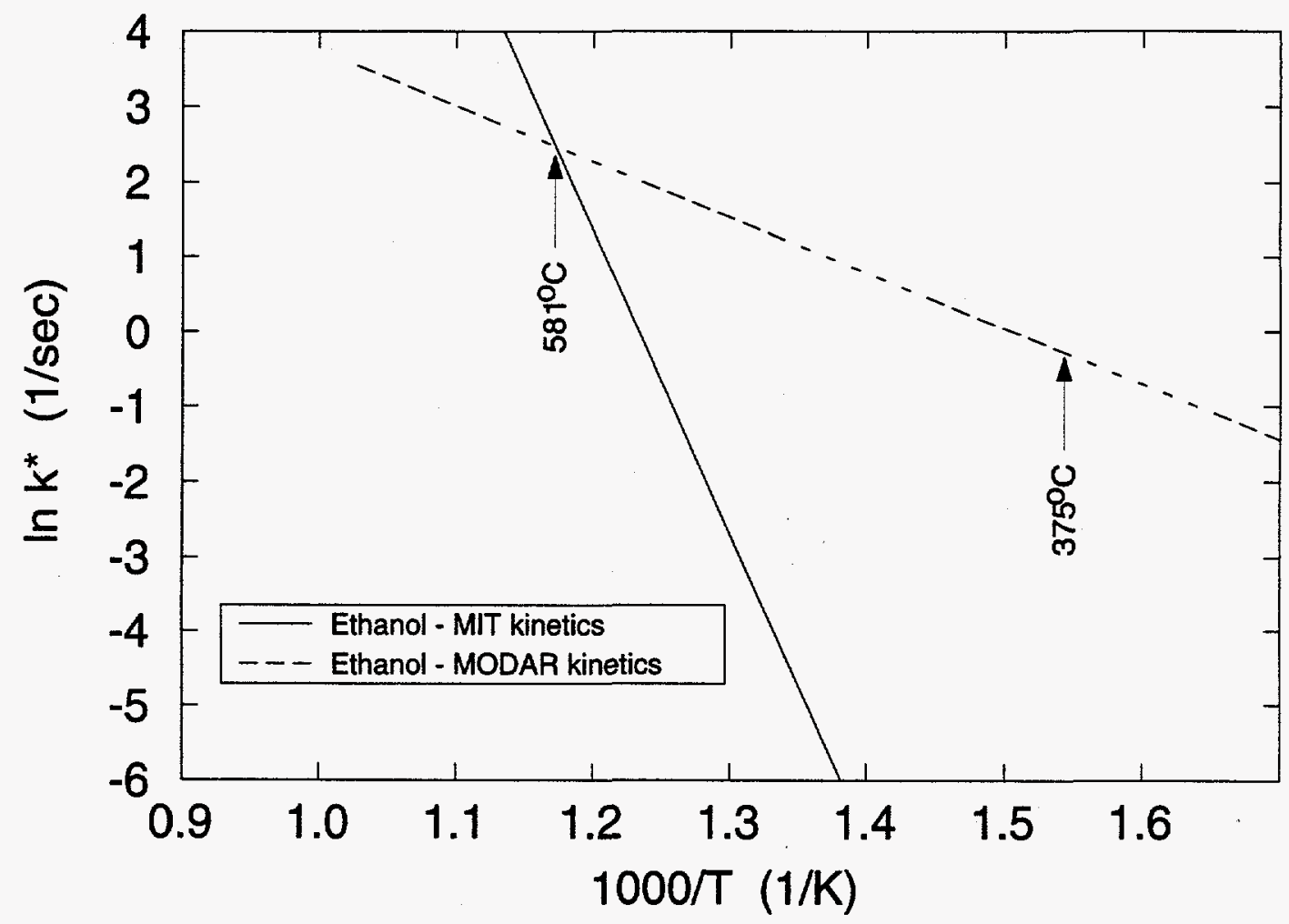

Figure 7. MIT and MODAR Arrhenius reaction rate curves for ethanol.

\subsection{Formation Enthalpies}

The formation enthalpies for all species entering into the chemical reactions, together with the reference temperatures at which these are defined, are required in the FLUENT model. The values used in these calculations were obtained from Reference 9 and are shown in the table below: 
Table 1. Specie formation enthalpies for SCWO of ethanol in air.

\begin{tabular}{|c|c|c|}
\cline { 2 - 3 } \multicolumn{1}{c|}{} & $\begin{array}{c}\text { Formation enthalpy } \\
(\mathrm{J} / \mathrm{kmol})\end{array}$ & $\begin{array}{c}\text { Reference } \\
\text { temperature } \\
(\mathrm{K})\end{array}$ \\
\hline \hline $\mathrm{C}_{2} \mathrm{H}_{6} \mathrm{O}$ & $-2.78 \mathrm{E} 08$ & 298.15 \\
\hline $\mathrm{H}_{2} \mathrm{O}$ & $-2.85 \mathrm{E} 08$ & 298.15 \\
\hline $\mathrm{CO}_{2}$ & $-3.94 \mathrm{E} 08$ & 298.15 \\
\hline $\mathrm{O}_{2}$ & 0 & 298.15 \\
\hline $\mathrm{N}_{2}$ & 0 & 298.15 \\
\hline
\end{tabular}

In the above table the formation enthalpies of ethanol and water were taken to be those of the liquid state, while that of $\mathrm{CO}_{2}$ was taken to be a gas.

\subsection{Boundary Conditions}

The FLUENT simulation boundary conditions were selected to represent the conditions for the latter (steady state) stages of MODAR Run 523. $\mathrm{F}^{\mathrm{a}}$. This case represents ethanol oxidation in supercritical water by an air oxidation stream. Boundary conditions used and rationale for their selection are detailed as follows:

1. The vessel was oriented vertically with inlet flows injected downward. Gravitational forces were included in the simulation.

2. A symmetry boundary condition was used at the vessel centerline.

3. The core flow consists of $6.2 \mathrm{lbm} / \mathrm{hr}$ of water and $1.05 \mathrm{lbm} / \mathrm{hr}$ of ethanol entering the reactor at $3500 \mathrm{psia}$ and $25^{\circ} \mathrm{C}$. A uniform velocity profile was assumed at the nozzle exit, i.e., to simplify the calculations, boundary layer development in the nozzle was ignored. The core inlet turbulence intensity was assumed to be $5 \%$.

4. The annular flow consists of $13.2 \mathrm{lbm} / \mathrm{hr}$ of air $(2.9 \mathrm{lbm} / \mathrm{hr} \mathrm{O} 2$ and $10.3 \mathrm{lbm} / \mathrm{hr} \mathrm{N} 2)$ at $3500 \mathrm{psia}$ and $200^{\circ} \mathrm{C}$. Annulus water was turned off in this simulation to match the conditions during the test run. A uniform velocity profile was assumed at the nozzle exit for the aforementioned reason. The core inlet turbulence intensity was assumed to be $5 \%$. 
5. The reactor side walls were maintained at a constant temperature of $600^{\circ} \mathrm{C}$ for the region of the wall covered by heaters. This simulated the heated walls of the test reactor better than the assumption of an adiabatic wall. Nozzle walls and reactor walls above the heated region were assumed to be adiabatic. No-slip velocity boundary conditions are assumed on these walls.

6. The bottom surface of the model is maintained at a constant temperature of $300^{\circ} \mathrm{C}$ to represent the upper surface of the reactor brine pool. A slip radial velocity boundary condition was used on this surface.

7. A constant pressure outlet was assumed.

\subsection{Turbulence Modeling}

FLUENT's renormalization group (RNG) turbulence model ${ }^{5}$ was selected for these calculations because of this model's reported accuracy in recirculating flows. This model follows the two-equation turbulence modeling framework and has been derived from the original governing equations for fluid flow using mathematical techniques called Renormalization Group methods. Based on this mathematical foundation to turbulence transport modeling, as opposed to semiempirical approaches that are more common, the RNG model provides a more general and fundamental model and yields improved predictions of near-wall flow (including flow separation), flows with high streamline curvature and high strain rate, low-Reynolds-number and transitional flow, wall heat/mass transfer, and detailed wake flow and vortex shedding behavior. 


\section{MODAR RUN 523.F RUN SERIES RESULTS}

The following sections present the updated results of the FLUENT simulation of MODAR Run 523.F in the form of plots of temperatures, concentrations of ethanol, and reaction heat sources. The results are limited to these parameters because they reflect the effect of most of the modeling changes presented in this document revision. The flow related parameters such as stream functions, velocities, and mixing parameters are essentially unchanged from those presented in Reference 3.

\subsection{Temperature Predictions}

Figure 8 shows the predicted temperature distribution in the entire reactor vessel. Peak fluid temperatures are shown to occur above the cold brine interface, between the brine interface and the recirculating region. These contours are smoother and more consistent than those presented in Reference 3 , especially near the reactor centerline where the profiles should have a zero slope. This is indicative of better numerical convergence with the current model.

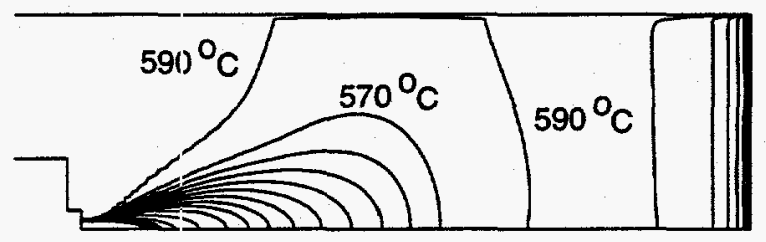

Figure 8. FLUENT predicted fluid temperatures for MODAR Run 523.f.

In order to completely validate the FLUENT model used in this study, it would be necessary to have measured temperatures and flows throughout the reactor vessel, at its inlets, and at its wall boundaries. Since this test run was not intended by MODAR to be used for rigorous code validation, this level of detail of data was not obtained. However, by using available data and engineering judgement where data was unavailable or uncertain, good estimates of the necessary data could be made for use in the compuer simulation.

In the region above the brine surface, we compared data from three temperature sensors with the calculated values. These include temperature sensor 408, 407, and 40DS (the latter sensor was in a region of the model in which the wall temperature was specified to be $600^{\circ} \mathrm{C}$ so it is not a totally independent calculated value). These temperatures are compared with fluid temperatures calculated by the FLUENT model in Figure 9. Agreement is good for the assumed conditions but the test data indicates a somewhat greater heat loss from the outlet section than predicted by the adiabatic wall assumption in the FLUENT model. The mixed outlet temperature from FLUENT is about $590^{\circ} \mathrm{C}$, slightly higher than the calculated adiabatic reaction temperature of $573^{\circ} \mathrm{C}$. This may be due to the small heat gain from the $600^{\circ} \mathrm{C}$ heated lower wall. The high local fluid temperature measured near the heated wall section is probably due to the proximity of the wall heaters. Because MODAR manually controls some of the test parameters, the test data during this 


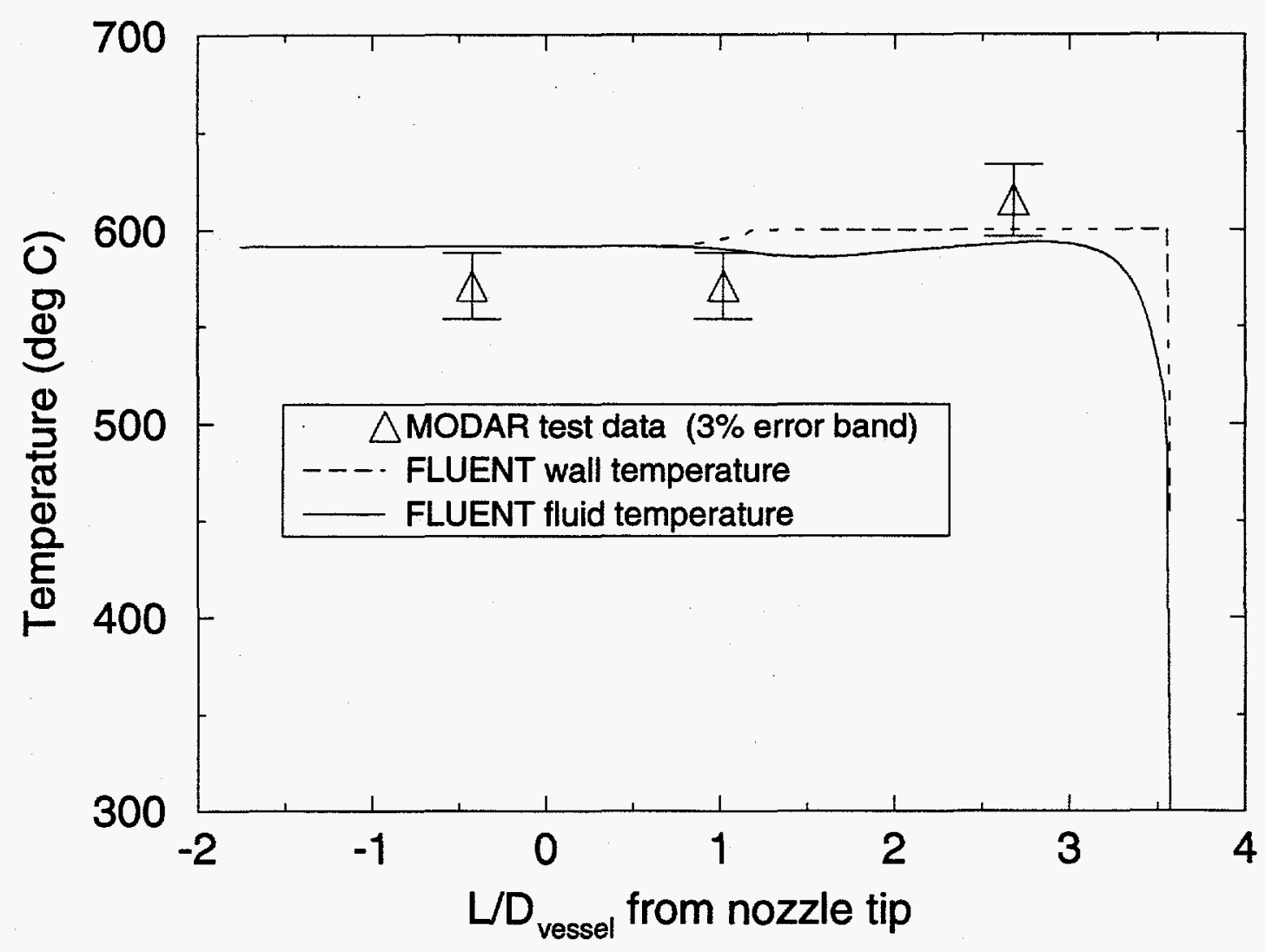

Figure 9. Comparison of MODAR test data with FLUENT predicted temperatures.

test series fluctuate by $10-15^{\circ} \mathrm{C}$ so the runs are only quasi-steady state. The agreement in temperatures is sufficient enough to provide confidence in the calculation of other reactor performance and hydraulic characteristics.

\subsection{Vessel Reactor Characteristics}

\subsubsection{Recirculation Pattern}

The streamfunctions calculated with this improved model are essentially identical to those presented in Reference 3 with the familiar large recirculation pattern downstream of the nozzle tip and a lack of streamlines in the vessel bottom portion. This recirculation pattern is important because it mixes hot reaction products into the oxidant stream and is a significant source of preheating energy for the reactants.

\subsubsection{Nozzle Mixing Zone}

The new calculations show that the mixing characteristics are unchanged from those presented in Reference 3 . The strong shear layers from each of the nozzle exits mix well both thermally and hydrodynamically in about one reactor diameter from the tip (well mixed flows are 
considered to be indicated by a parabolic profile representative of a single jet rather that the two jets that actually exit the nozzle.)

\subsubsection{Critical Properties}

As discussed previously, there is a large spike in the water heat capacity at its critical temperature (about $374^{\circ} \mathrm{C}$ at $3400 \mathrm{psia}$ ). These property variations made the $\mathrm{CFD}$ solution converge poorly and required that the specific heat curve be approximated by a smooth function as discussed previously. In order to determine the extent of the region impacted by the water specific heat approximation (between 327 and $427^{\circ} \mathrm{C}$ ), Figure 10 is presented.

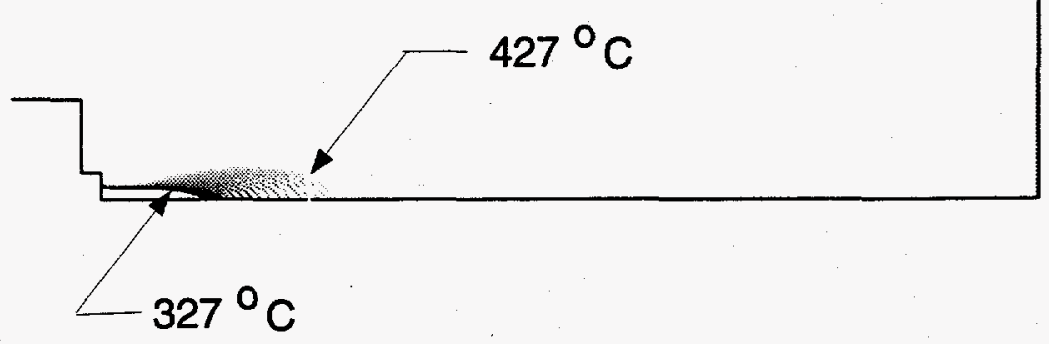

Figure 10. Region of the reactor with temperatures between 327 and $427^{\circ} \mathrm{C}$. Peak water specific heat is at $379^{\circ} \mathrm{C}$.

This figure shows that there is one primary region in the reactor that has temperature transitions through this range. This is the reaction zone in which the low temperature core flow heats up through the critical temperature due to mixing and oxidation. The domain of approximation of water properties is seen to be small; in these regions the fluid temperatures are approximate but outside these regions they should be accurate. Another small region, that doesn't show well in this figure, is the region of the brine pool where the cold water pool meets the high temperature reaction products at the effective bottom of the reactor. This transition is not as important to the simulation since it is not in the reaction zone.

\subsubsection{MIT vs. MODAR Kinetic Constants}

In order to be able to model the many fluids capable of being oxidized with the SCWO process, an insight into the effect of the temperature sensitivity of the Arrhenius rate equation on the CFD results needs to be determined. The slope of the rate equation doesn't affect the peak reaction temperatures (as represented by' the adiabatic reaction temperatures). Because essentially all of the fuel is oxidized, the reaction temperatures are determined by the energy input into the system and the effective heat capacities. However, the rate equation does have a direct effect on the reaction distribution (shape of the reaction zone) and, as such, has a major effect on whether a combination of flows with a given heating value will sustain a stable reaction. 
An additional simulation was made to determine the effect of using the MODAR kinetic constants instead of the MIT values used in most of the runs in this report. The MODAR rate constants were obtained in a non-isothermal reactor in which hot and cold streams were reacted, while the MIT rate constants were obtained in an isothermal experiment.

Figure 11 shows a comparison of the effect of the different Arrhenius rate equations on the calculated ethanol reaction rate, ethanol mass fraction, and fluid temperature. The major difference, as expected, is in the predicted reaction rates. As Figure 7 showed, the MIT reaction rates are much lower at the lower temperatures in the mixing zone just downstream of the nozzle exit. The temperatures in this zone must be raised by entraining hot products to allow a significant reaction rate to occur, especially for the MIT rate equation. For the MODAR rate equation the reactions are vigorous immediately outside of the nozzle. Since both of these cases result in complete oxidation, the reaction rates and other parameters are similar in the portions of the reactor outside of the mixing zone.

Differences in the ethanol mass fractions are also small and primarily occur in the mixing zone. Destruction is complete by the time the fluid reaches the brine pool or the effluent outlet, as evidenced by the low ethanol mass fractions at these locations. The outlet ethanol mass fractions are over several orders of magnitude lower than the inlet value of 0.14 .

Small differences in the fluid temperatures are found only in the mixing zone. In regions where the oxidation is complete, the temperatures are essentially identical.

FLUENT uses the lower of the reaction rates calculated by using the Arrhenius rate equation or turbulent mixing calculations to calculate the heat released by chemical reactions. Figure 12 shows the ratio of the Arrhenius/mixing reaction rates for both the MIT and the MODAR kinetic rate equations. A ratio of 1 is the boundary between kinetic and diffusion limited reaction rates: below a ratio of 1 , the reactions are kinetically limited. It is seen from this figure that most of the reacting zone is in the kinetics limited regime. This is consistent with the comparison of the MIT and MODAR results in the mixing zone noted in Figure 11 .

It is important to note that the difference in overall organic destruction is very similar between these two sets of kinetic rates, even though they are orders of magnitude different at the lower temperatures representative of the mixing zone. This indicates that this vessel reactor is tolerant to significant differences in reaction rate curves as long as the residence time is long enough to allow complete destruction. 


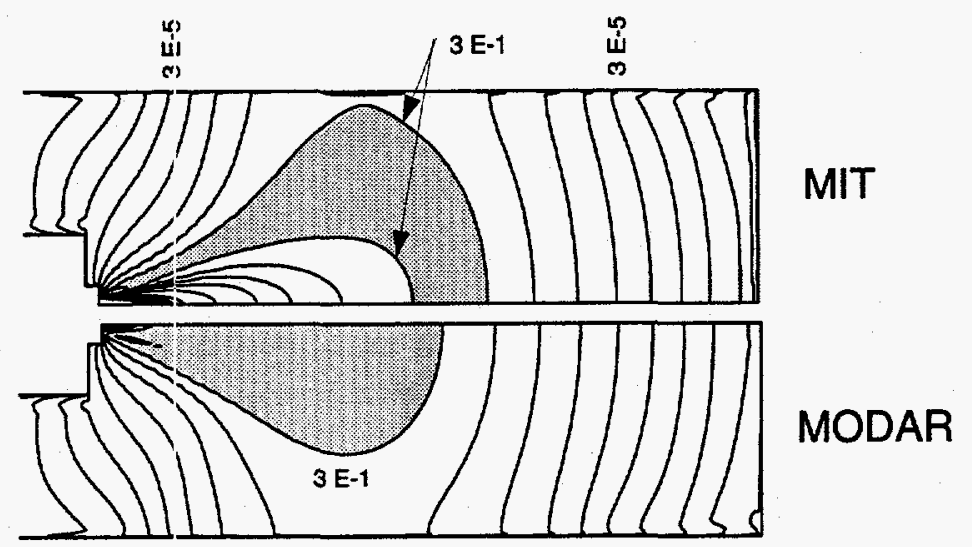

\section{Ethanol reaction rate $(\mathrm{kg} / \mathrm{m} 3-\mathrm{sec})$}

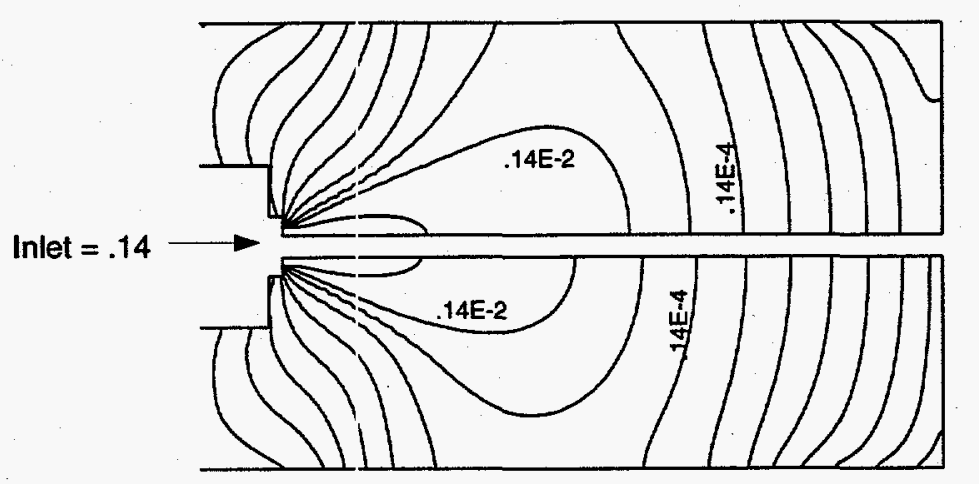

MIT

MODAR

\section{Ethanol mass fraction}

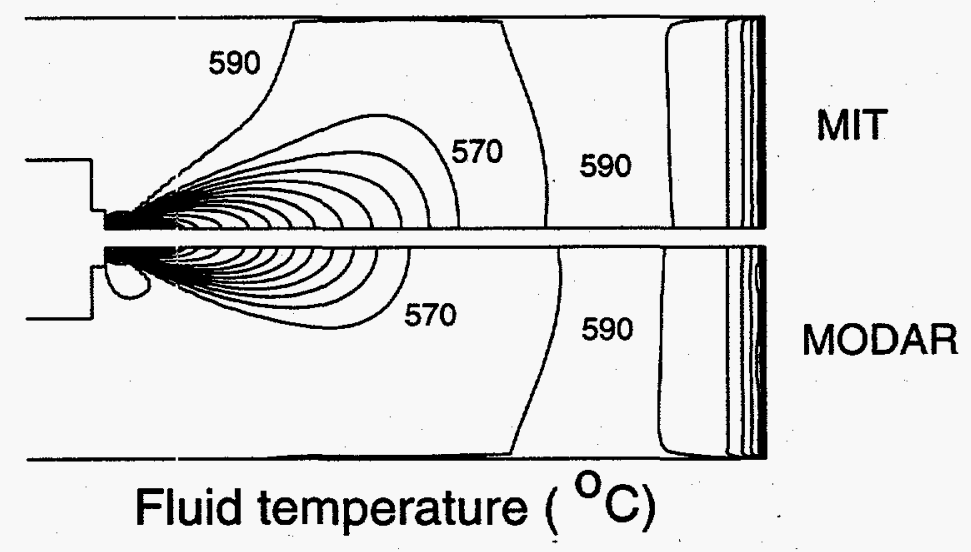

Figure 11. Comparison of FLUENT results using MIT and MODAR kinetic rate equations. Reaction rate and mass fraction contours are factors of 10 ; fluid temperatures are $20^{\circ} \mathrm{C}$. Shaded areas in reaction rates show regions of highest rates. 


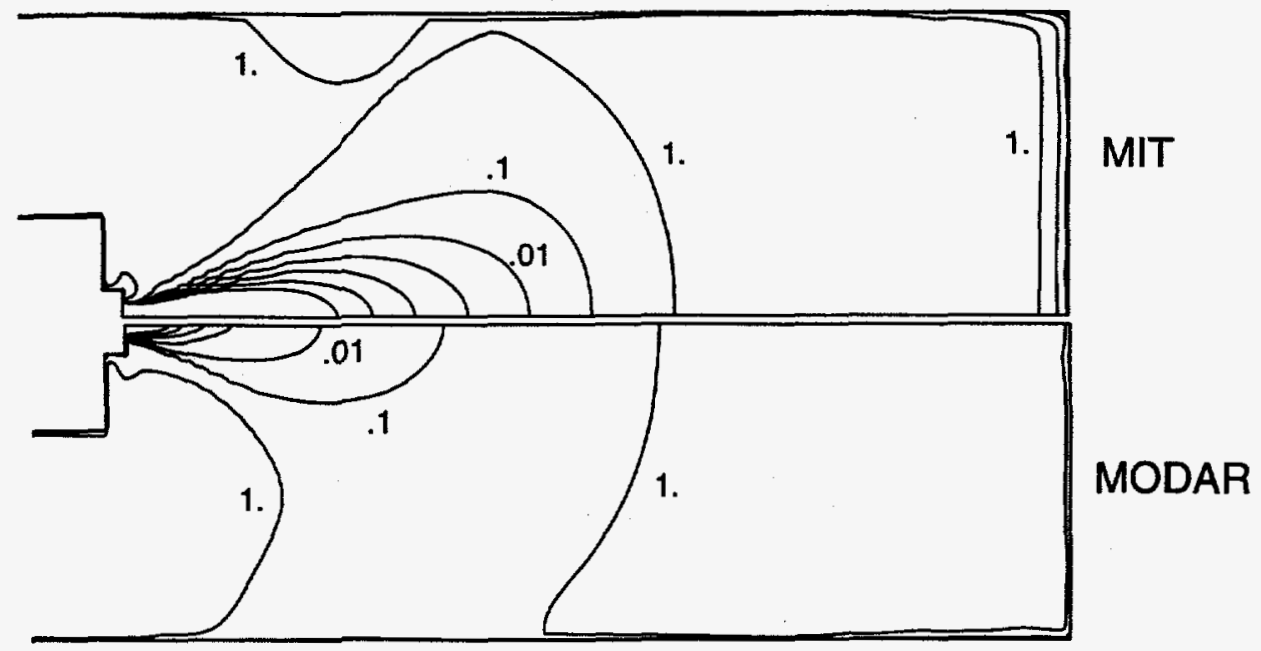

Figure 12. Arrhenius/Mixing reaction rate ratios for MIT and MODAR rate equations. Levels below 1 are kinetics limited; greater than 1 are diffusion limited. 


\section{CONCLUSIONS AND RECOMMENDATIONS}

These initial validations of the FLUENT model of a SCWO vessel reactor show that the FLUENT CFD code can be sucessfully used to evaluate the complex fluid-chemical kinetic interactions occurring in the reactor. It is apparent that future tests need to be carefully instrumented so that all boundary flows and temperatures can be accurately measured. More complete test data would allow a better validation of the reactor model and code.

There are several areas of the modeling that need to be addressed further so that they can be improved on for future applications:

1. The approximation of the water heat capacity in the vicinity of the critical point has already been discussed. The technique used in this study performed adequately but perhaps the region of influence could be shrunk by using a narrower temperature range.

2. This model is relatively large (14,300 cells) for a 2 -D model and takes days to converge after perturbation of the boundary conditions. We need to investigate a cruder model that will still give adequate results in comparison with this detailed model. This will allow more extensive parameter studies in a reasonable amount of time.

3. In contrast to the previous bench scale results, this analysis shows that most of the reaction zone is in the kinetic controlled regime because the kinetic rates (from either the MIT or the MODAR rate coefficients) are low in the mixing region. The kinetic rate equation was found to have a significant effect on the rate distributions in the mixing zone. In this zone the reaction is mixing limited. Outside of the mixing zone the rates are similar because the two rate equations give similar results at the higher temperatures. These results show that as long as there is sufficient residence time to allow complete oxidation, the effect of the rate equation is minimal on the reactor performance.

4. Salt transport in the reactor vessel needs to be modeled to obtain an insight into regions of salt buildup. This can be coupled with a study of nozzle performance related to mixing characteristics and salt transport. 


\section{REFERENCES}

1. R.J. Kochan and C.H. Oh, Preliminary Analytical Modeling Requirements for Thermal Hydraulic Analysis of SCWO Pilot Plant, EG\&G Idaho, Inc., EGG-WTD-10985, November 1993.

2. R.J. Kochan and C.H. Oh, "Preliminary CFD Computer Code Comparison for ThermalHydraulic Analysis of SCWO Reactor," INEL TDF \#ID121217/1020, May 26, 1994.

3. R.J. Kochan and C.H. Oh, CFD Code Selection and Preliminary Validation for ThermalHydraulic Analysis of SCWO Benchscale Reactor, Idaho National Engineering Laboratory, INEL-94/0224, December 1994.

4. R.J. Kochan and C.H. Oh, CFD Model Development and Data Comparison for ThermalHydraulic Analysis of HTO Pilot Scale Reactor, Idaho National Engineering Laboratory, INEL-95/0445, (TBD) 1995.

5. FLUENT User's Guide Version 4.3 and FLUENT Code Release of Version 4.3.1, January 1995.

6. ASPEN Technology, Inc., ASPEN PLUS Release 9 Manual, 1994.

7. L. Haar et. al., NBS/NRC Steam Tables, Hemisphere Publishing Corporation, New York, 1984.

8. G.P. Jacobs et al., "Utilization of PHOENICS in the Design of the MODAR SCWO Reactor, "Presented in Session of Reactions in Supercritical Fluids," 1992 Annual AIChE Meeting, Miami Beach, Florida, November 1-6, 1992.

9. D.M.Himmelblau, Basic Principles and Calculations in Chemical Engineering, 5th Edition, Prentice Hall, New Jersey, 1989. 